\title{
Insights into the Dynamics of Grotthuss Mechanism in a Proton- Conducting Chiral bioMOF
}

Thais Grancha, ${ }^{\dagger}$ Jesús Ferrando-Soria, ${ }^{\dagger}$ Joan Cano, ${ }^{\dagger,}$ ' Pedro Amorós, ${ }^{\S}$ Beatriz Seoane,,$\|$ Jorge Gascon, *,\| Montse Bazaga-García, ${ }^{\perp}$ Enrique R. Losilla, ${ }^{\perp}$ Aurelio Cabeza, ${ }^{\perp}$ Donatella Armentano, ${ }^{*}, \downarrow$ and Emilio Pardo* ${ }^{*}$

${ }^{\dagger}$ Departament de Química Inorgànica, Instituto de Ciencia Molecular (ICMOL), Universitat de València, 46980 Paterna, València, Spain

${ }^{\ddagger}$ Fundació General de la Universitat de València (FGUV), Universitat de València, 46980 Paterna, València, Spain

${ }^{\S}$ Institut de Ciència dels Materials (ICMUV), Universitat de València, E-46980 Paterna, Valencia, Spain

"Catalysis Engineering Department, Delft University of Technology, Julianalaan 136, 2628 BL Delft, The Netherlands

${ }^{\perp}$ Depto. Química Inorgánica, Universidad de Málaga, Campus de Teatinos s/n, Málaga-29071, Spain

${ }^{\nabla}$ Dipartimento di Chimica e Tecnologie Chimiche, Università della Calabria, Rende 87036, Cosenza, Italy

Supporting Information

ABSTRACT: Proton conduction in solids attracts great interest, not only because of possible applications in fuel cell technologies, but also because of the main role of this process in many biological mechanisms. Metal-organic frameworks (MOFs) can exhibit exceptional proton-conduction performances, because of the large number of hydrogen-bonded water molecules embedded in their pores. However, further work remains to be done to elucidate the real conducting mechanism. Among the different MOF subfamilies, bioMOFs, which have been constructed using biomolecule derivatives as building blocks and often affording water-stable materials, emerge as valuable systems to study the transport mechanisms involved in the proton-hopping dynamics. Herein, we report a versatile chiral threedimensional (3D) bioMOF, exhibiting permanent porosity, as well as high chemical, structural, and water stability. Moreover, the choice of this suitable bioligand results in proton conductivity, and allows us to propose a proton-conducting mechanism based on experimental data, which are displayed visually by means of quantum molecular dynamics simulations.

\section{INTRODUCTION}

Metal-organic frameworks (MOFs) $)^{1-3}$ are extensively studied due to the large variety of physical and chemical properties that they can exhibit, ${ }^{4,5}$ which are often related to their intrinsic porous character and rich host-guest chemistry. Besides, the design of highly robust, thermal- and water-stable (including also acid and basic media) MOF materials becomes highly relevant to facilitate good performance for potential applications. $^{6}$

In this context, MOFs have recently become very relevant to achieve water-mediated proton ${ }^{7-29}\left(\mathrm{H}^{+}\right)$or hydroxide $\left(\mathrm{OH}^{-}\right)$ ion $^{30}$-conducting materials, which can find application in fuel cells. ${ }^{8}$ This phenomenon is intimately related to the large amount of disordered water molecules, acting as proton carriers, hosted in their channels. Despite the relatively large number of MOFs showing excellent performance in proton conduction and recent advances into the understanding of the dynamics of proton transport in MOFs, ${ }^{31}$ further work remains to be done to determine the real structure of the hydrogenbonded network involved in proton conduction.

A quite recent step forward toward the design of original examples of MOFs consists of the use of biomolecules as ligands to construct high-dimensional coordination networks, called bioMOFs. ${ }^{32,33}$ This subclass of materials offer, among other advantages, a more feasible moisture stability. Closely related to this last point, it has been established that water typically participates in molecular recognition and association in the solid state. Several studies further demonstrate that water thermodynamics is strictly dependent on the specific physicochemical properties of the confining environment. ${ }^{34}$ Hence, the choice of a suitable bioligand may well succeed in the challenging task of affording water-stable bioMOFs with a large number of water molecules embedded within their pores.

Received: March 31, 2016

Revised: June 13, 2016

Published: June 13, 2016 
<smiles>[R7][C@@H](NC(=O)C(=O)NC([R])([R7])C(=O)O)C(=O)O</smiles>

$$
\mathrm{H}_{4} \mathrm{~L}
$$
( $\mathrm{R}=\mathrm{Me}$ )

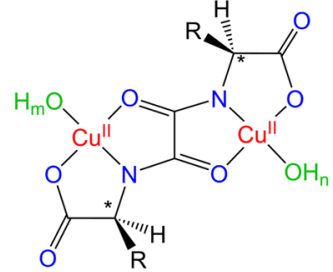

$\left[\mathrm{Cu}_{2} \mathrm{~L} \mathrm{~L}\left(\mathrm{OH}_{\mathrm{m}}\right)\left(\mathrm{OH}_{n}\right)\right]^{(4-m-n)-}$ $(m, n=1$ or 2$)$

b

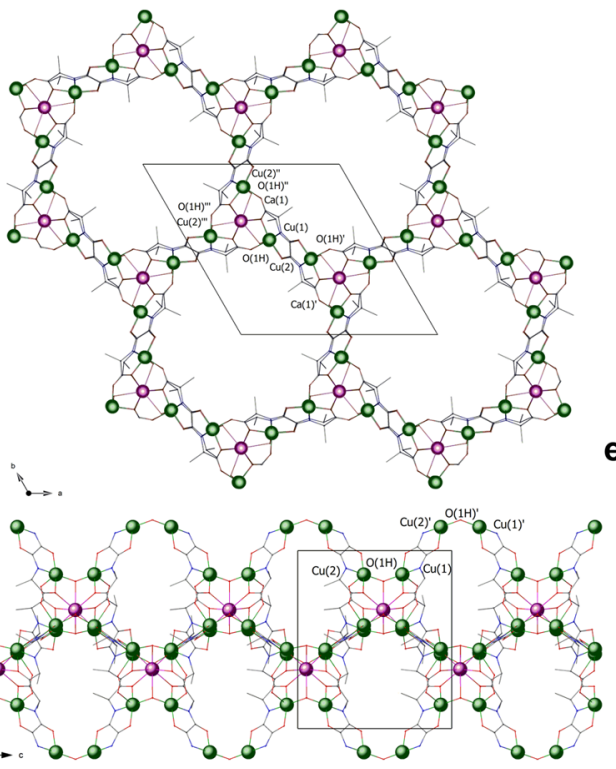

d
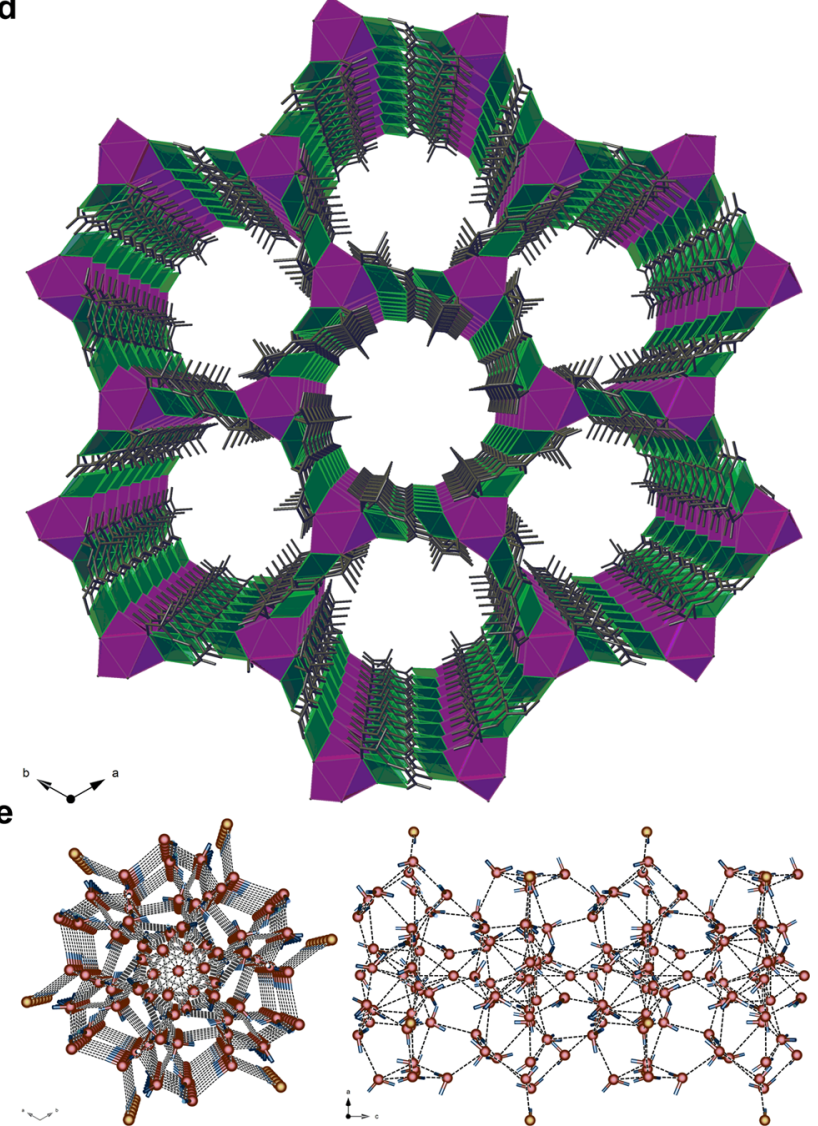

Figure 1. (a) Chemical structures of the chiral bis(amino acid)oxalamide ligands (left), highlighting the potential coordination sites and chiral centers and the corresponding dianionic bis(hydroxo) dicopper(II) complexes (right). Views of a fragment of $\mathbf{1}$ in the (b) $a b$ and (c) $b c$ planes, respectively, with the atom numbering scheme (symmetry code: (I) $=-x,-y+1, z+{ }^{1} / 2 ;(\mathrm{II})=-y+1, x-y+1, z ;$ (III) $\left.=-x+y,-x+1, z\right)$. (d) Perspective view of the three-dimensional (3D) open framework of 1 along the $c$-axis (the crystallization water molecules are omitted for clarity). (e) Views along the crystallographic $c$-axis (left) and $a$-axis (right) of the array of hydrogen-bonded guest water molecules and hydroxide anions located in each hexagonal channel. $\mathrm{Cu}$ and $\mathrm{Ca}$ atoms are represented by green and purple spheres or polyhedra, respectively, whereas the ligands are depicted as sticks. The $\mathrm{H}$ atoms, when present, are represented as blue sticks, whereas the water molecules and hydroxide anions are depicted as red and orange spheres. Hydrogen bonds are represented by dotted lines.

This would occur in an ordered manner, through a process of molecular recognition, even more dynamic in the presence of proton conduction. However, despite these clear advantages and the growing interest in bioMOFs, no examples of these systems exhibiting proton conduction have been reported so far.

Previous results on disubstituted oxamidato ligands derived from natural amino acids are used as a basis ${ }^{35-37}$ (see Figure 1a). Herein, we report a novel proton-conducting, chiral bioMOF, of formula $\left\{\mathrm{Ca}^{\mathrm{II}} \mathrm{Cu}_{6}{ }_{6}^{\mathrm{II}}[(\mathrm{S}, S) \text {-alamox }]_{3}(\mathrm{OH})_{2}\left(\mathrm{H}_{2} \mathrm{O}\right)\right\}$. $32 \mathrm{H}_{2} \mathrm{O}$ (1) $\left[\mathrm{H}_{4}-(S, S)\right.$-alamox $=N, N^{\prime}$-bis $((S)$-2-propanoic acid)oxamide, Figure la (left), with $\mathrm{R}=\mathrm{Me}$ ] exhibiting high chemical, thermal, and water stability (up to alkaline ( $\mathrm{pH} 14$ ) aqueous media). For the first time, the high-quality refinement of the crystal structure of 1 -showing the positions of the water molecules and their hydrogen atoms-allows to propose a conduction mechanism in a proton-conductive MOF, which is fully supported by structural and theoretical data.

\section{RESULTS AND DISCUSSION}

Synthesis and X-ray Crystal Structure. Compound 1 crystallizes in the chiral P63 space group of the hexagonal system. Its structure consists of a chiral 3D calcium(II)copper(II) network, which is built up from trans oxamidato- bridged dicopper(II) units, $\left\{\mathrm{Cu}_{2}[(S, S)\right.$-alamox $\left.]\right\}$, acting as linkers between the $\mathrm{Ca}^{\mathrm{II}}$ ions through carboxylate; further aqua/hydroxo groups (1:2 statistical distribution), acting as additional bridges between two neighboring dicopper(II) units and coordinated in a $\mu^{3}$ fashion, support the entire system, unfolding an uninodal six-connected net of $\left(4^{9} .6^{6}\right)$ Schläfli symbol (see Figure 1 and Figure $S 1$ in the Supporting Information).

Overall, 1 can be described as a mixed oxamidate- and carboxylate(aqua/hydroxo)-bridged, honeycomb-like hexagonal $3 \mathrm{D} \mathrm{Ca}^{\mathrm{II}} \mathrm{Cu}_{6}{ }_{6}$ open framework showing relatively large hexagonal channels along the $c$-axis (Figure $1 \mathrm{~d}$ ), which are occupied by crystallization water molecules (see Figures 1e, as well as Figures S1 and S2 in the Supporting Information). These channels have a virtual diameter of ca. $1.0 \mathrm{~nm}$, resulting from the alternating orientation of the methyl residues from the trans-(S,S)-alamox bridging ligands within adjacent channels. The estimated empty volume without the crystallization water molecules is $2089.1 \AA^{3}$, which is a value that represents up to ca. $58.0 \%$ of potential void per unit cell volume $\left[V=3604.1 \AA^{3}\right]$ (Figure S3 in the Supporting Information). A striking structural feature of $\mathbf{1}$ is that all water molecules hosted in the pores are hydrogen-bonded, forming one-dimensional (1D) ribbons 
along the $c$-axis (see Figure 1e) that involve the aqua/hydroxo bridges of the network.

Thermogravimetric Analysis and Powder X-ray Diffraction. Thermogravimetric analysis (TGA) shows a mass loss at $473 \mathrm{~K}$ of $31.5 \%$ (Figure $\mathrm{S} 4$ in the Supporting Information) which corresponds to $30 \mathrm{H}_{2} \mathrm{O}$ molecules per formula unit, a value close to the 32 lattice molecules found in the crystal structure determined by single-crystal X-ray diffraction (SCXRD) at $90 \mathrm{~K}$. The vapor water adsorption isotherm of 1 at $25{ }^{\circ} \mathrm{C}$ shows that the complete rehydration process, with the recovery of $32 \mathrm{mmol}$ of water per mmol of bioMOF, can be only achieved under maximum relative humidity (see Figure S5 in the Supporting Information), which is in complete agreement with the proton conductivity measurements (see below).

Powder X-ray diffraction (PXRD) studies were carried out on a polycrystalline sample of 1 (Figure 2). PXRD patterns

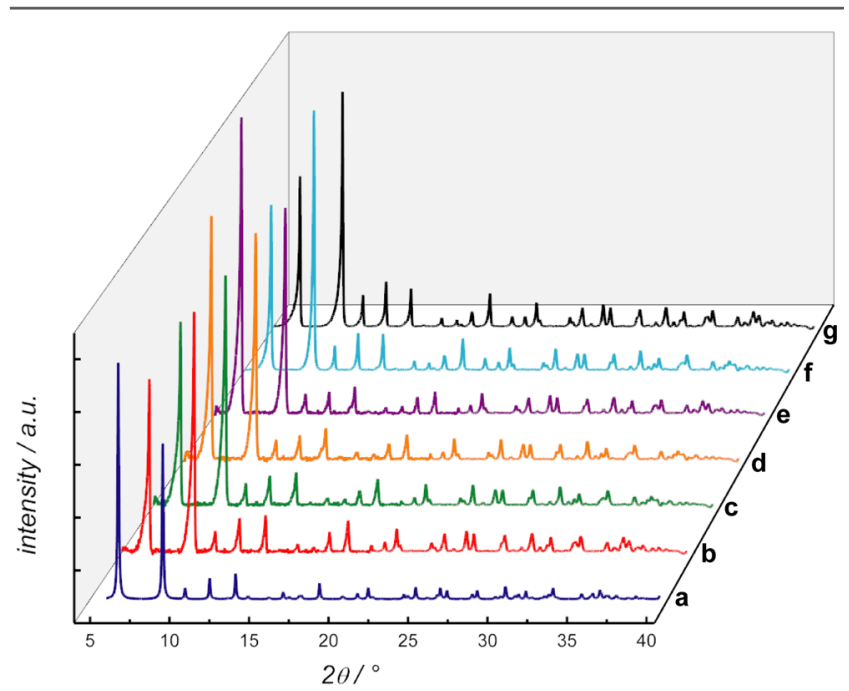

Figure 2. (a) Calculated PXRD pattern profile of $\mathbf{1}$ (pattern profile a). Variable-temperature XRD patterns of the activated phase of $\mathbf{1}$ at 298 $\mathrm{K}$ (pattern profile b), $343 \mathrm{~K}$ (pattern profile c), (d) $353 \mathrm{~K}$ (pattern profile $\mathrm{d}$ ), and $370 \mathrm{~K}$ (pattern profile e). PXRD pattern profiles of 1 after proton conduction measurements (pattern profile $\mathrm{f}$ ) and (pattern profile $\mathrm{g}$ ) after 1 month of immersion in a $\mathrm{pH} 14$ aqueous solution at room temperature (RT).

show the retention of crystallinity over the entire range of temperatures studied, confirming the structural robustness of the material upon water loss (Figures 2, pattern profiles b-e). In addition, the structural stability of this bioMOF was further verified both after proton conductivity experiments (pattern $\mathrm{f}$ in Figure 2) and also in basic aqueous media by immersion in a $\mathrm{pH} 14$ aqueous solution for one month (pattern g in Figure 2).

The permanent porosity of $\mathbf{1}$ was demonstrated by means of $\mathrm{N}_{2}$ adsorption at $77 \mathrm{~K}$. The isotherm shows a type I behavior with large uptake at low pressures (Figure 3). The BrunauerEmmett-Teller (BET) surface area calculated was $1015 \mathrm{~m}^{2} /$ g, ${ }^{38,39}$ with a calculated pore size ${ }^{40}$ of $1.1 \mathrm{~nm}$, which closely corresponds to that determined from the crystal structure.

Proton Conductivity Measurements and Conducting Mechanism. Considering the strong interest observed recently in proton conductors, ${ }^{7-29,31}$ together with the presence of an array of hydrogen-bonded water molecules along the hexagonal channels in $\mathbf{1}$ (see Figure 1e, as well as Figures S1 and S2), we performed ionic conductivity measurements.

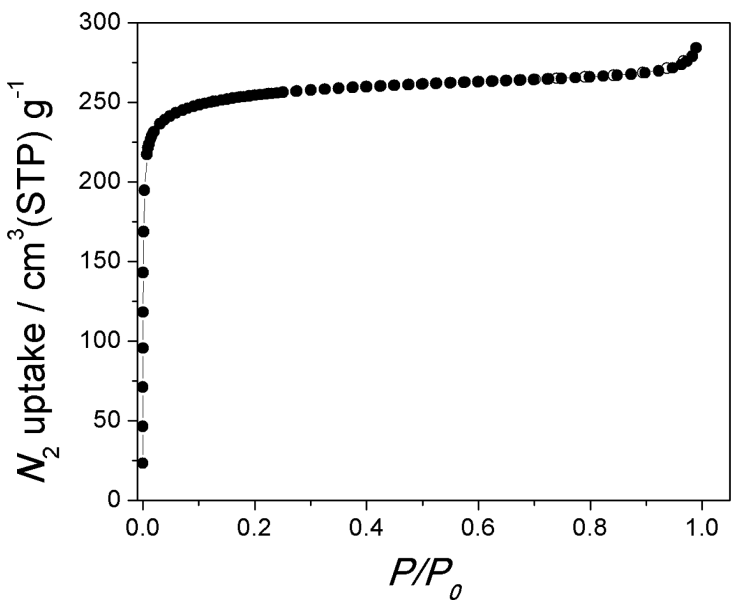

Figure 3. $\mathrm{N}_{2}(77 \mathrm{~K})$ adsorption isotherm for the activated compound 1. Filled and empty symbols indicate the adsorption and desorption isotherms, respectively.

Impedance data in the form of a complex plane plot for $\mathbf{1}$ at $353 \mathrm{~K}$ and different relative humidity values $(\mathrm{RH})$, after full equilibration of the measurements (Figure S6), are shown in Figure 4a. The data show an overlapped/deformed broad arc at high frequencies/low $\mathrm{RH}$ with an associated capacitances of $\sim(2-3) \times 10^{-11} \mathrm{~F} \mathrm{~cm}^{-1}$. With increasing $\mathrm{RH}$, lower frequency effects are seen, in the form of an inclined spike with an associated capacitances of $\sim 8-10 \mu \mathrm{F} \mathrm{cm}{ }^{-1}$, which indicates a partial-blocking electrode response consistent with proton migration. The structural stability of this MOF after postimpedance measurements was checked by X-ray diffraction and thermal analysis. The TG curves do not show changes in the water content for the different environmental conditions tested (Figure S4) suggesting the easy loss of two water molecules when exposed to air-further confirmed by crystal structure determined by SCXRD at room temperature (see the Supporting Information) - which can be only fully recovered within the humidity chamber. Furthermore, the PXRD patterns after the measurements are consistent with the theoretical one (Figure 2f).

The conductivity of $\mathbf{1}$ increases with the relative humidity (Figure 4a), which is characteristic of many water-mediated proton conductors. For instance, the conductivity at $353 \mathrm{~K}$ increases from $1.1 \times 10^{-6} \mathrm{~S} \mathrm{~cm}^{-1}$ at $60 \% \mathrm{RH}$ up to $8.6 \times 10^{-4} \mathrm{~S}$ $\mathrm{cm}^{-1}$ at $95 \% \mathrm{RH}$. The proton conductivity for 1 measured at $297 \mathrm{~K}$ and $95 \% \mathrm{RH}, 1.0 \times 10^{-5} \mathrm{~S} \mathrm{~cm}^{-1}$, is comparable with other carboxylate-based MOFs. ${ }^{41}$ Figure $4 \mathrm{~b}$ displays the overall pellet conductivities in traditional Arrhenius plots as a function of RH. These plots show a linear behavior with activation energies $\left(E_{\mathrm{a}}\right)$ of $0.42,0.43,0.42$, and $0.34 \mathrm{eV}$ for $\mathrm{RH}$ values of $60 \%, 70 \%, 80 \%$, and $95 \%$, respectively. These relatively small numbers are within the range typically attributed to a Grotthuss transfer mechanism via water molecules $(0.1-0.5 \mathrm{eV}) .^{42-46}$

These results suggest that, even in the absence of free acid or basic groups in the framework, the presence of a hydrogenbonded intricate chain involving both the free water and the coordinated hydroxo/water molecules is enough to develop moderate ionic conductivity. Although a vehicle mechanism ${ }^{47}$ contribution cannot be discarded, this conductivity most-likely arises from the proton hopping through the hydrogen-bonded array of water molecules, as expected for a structure diffusion mechanism, ${ }^{48,49}$ as reported previously in theoretical-experimental studies in pure water ${ }^{50-52}$ or acid aqueous solutions. ${ }^{53}$ 
a)

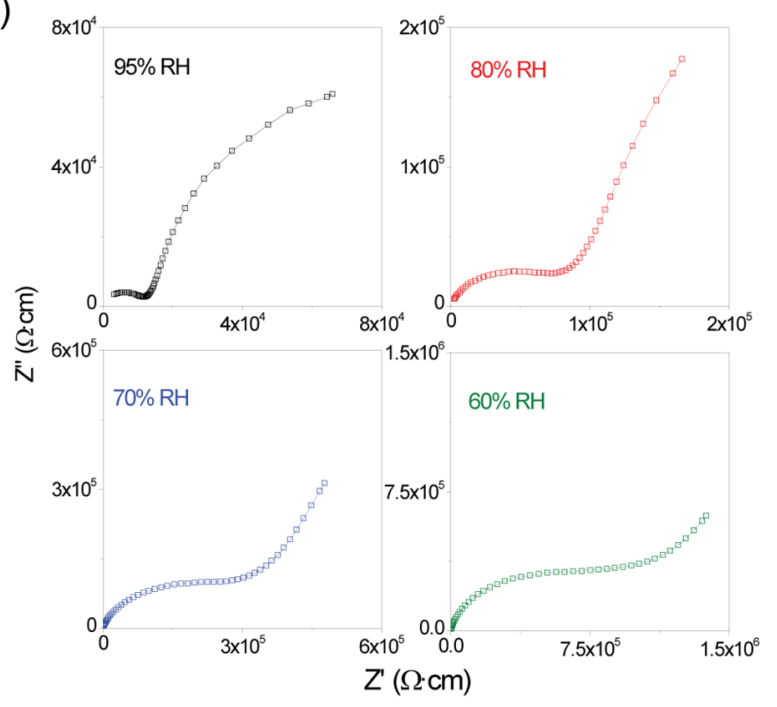

b)

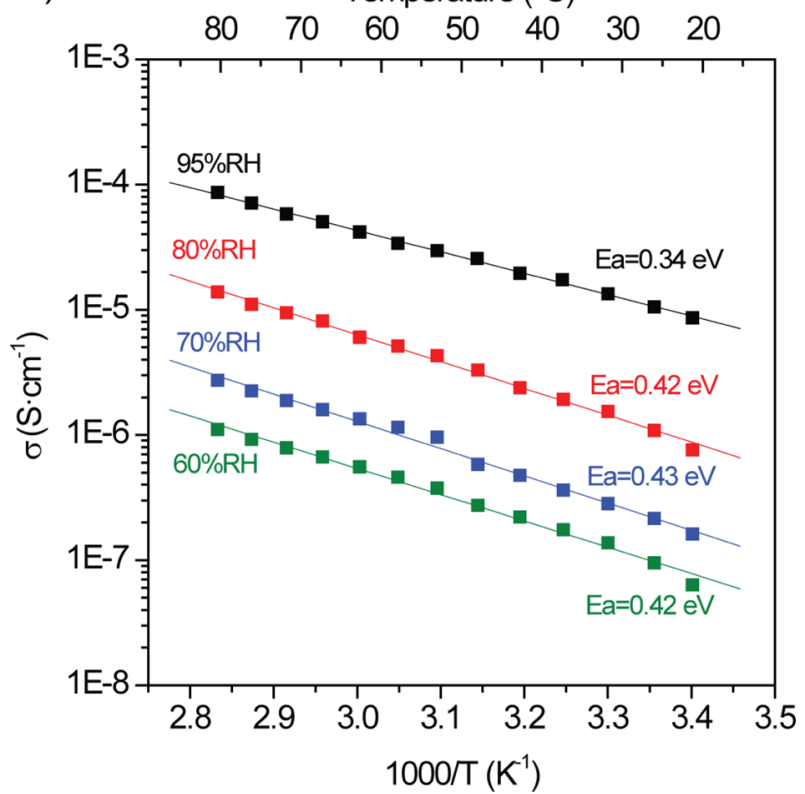

Figure 4. (a) Nyquist plots for compound 1 at $353 \mathrm{~K}$ under four different relative humidity $(\mathrm{RH})$ values. Solid lines indicate the fitting to the equivalent circuit $(\mathrm{RbQb})(\mathrm{RgbQgb})(\mathrm{Qe})$. (b) Protonic conductivity data of $\mathbf{1}$ versus reciprocal temperature (Arrhenius plot) at four selected $\mathrm{RH}$ values. Activation energies were highlighted.

It is clear that proton transport mechanisms in solids attract great interest, because of their relation to many natural processes $^{54}$ and its potential application in a wide variety of electrochemical and energy-conversion devices. ${ }^{8}$ However, the vast majority of theoretical studies, with regard to the mechanism of proton conduction (most of them of theoretical nature), could only carried out so far in nonporous solids. ${ }^{55-59}$ In contrast, despite the fact that MOFs show excellent results as proton-conducting materials-they exhibit large pores, which allows the movement of ions, as well as the presence of guest carrier molecules ${ }^{24,60}$ - the first joint experimental/theoretical study dealing with the proton-conduction mechanism in a MOF was published only very recently. ${ }^{31}$ This outstanding feature is undoubtedly related to the high disorder of the solvent molecules.
In a recent work, ${ }^{28}$ Kitagawa et al. suggested that "only MOFs having small pores should be employed to construct visible proton-conducting pathways". This would be based on the reasonable assumption that disorder increases with increasing pore size. However, despite the large pores, water molecules hosted in the channels of $\mathbf{1}$ are particularly ordered and their positions-including those of their hydrogen atoms and, thus, the directionality of the hydrogen bond-could be undoubtedly allocated. With this information in hand, we are able to propose a clear conduction mechanism in a protonconductive MOF, in clear agreement with the recent findings shown by Damasceno et al. ${ }^{31}$

Figure le shows the hydrogen-bonded pathways developing inside one hexagonal channel in $\mathbf{1}$. At first sight, it is reasonable to suppose that several concerted tautomeric equilibriums should be followed in the channels (and in other protonconducting MOFs). We focus just on a few of them to suggest a model consistent with the experimentally located hydrogen atoms. The observed pattern of atomic positions in the waterbranched chain is reliable with a hopping of protons between neighboring and hydrogen-bonded water molecules, which is consistent with a Grotthuss-like mechanism. ${ }^{48}$ The distances crossed by the $\mathrm{H}$ atoms in the hopping process range from $0.73(4) \AA$ to $1.14(1) \AA$ with corresponding $\mathrm{O} \cdots \mathrm{O}$ separations varying in the range of $2.686(10)-2.957(9) \AA$ (detailed values in Table S1 in the Supporting Information).

The proposed mechanism is detailed as follows: Figure 5a represents the starting situation found in the crystal structure, whereas Figures $5 \mathrm{~b}$ and $5 \mathrm{c}$ show the proposed intermediate stages with the proton hopping between neighboring molecules and their consecutive reorientation to finally recover the original situation (Figure $5 \mathrm{~d}$ ). Their orientations represent always a valid structure for the water net. We choose as the proton transfer starting point $\mathrm{O} 2 \mathrm{~W}$, which can initiate two different pathways: toward O9W (path 1) or toward O1W (path 2). Afterward, the two pathways must follow the labeled way of path 1 /path 2 or exhibit a possible deviation (path $1^{\prime}$ or path $2^{\prime}$ ), which is logical, given that an efficient concerted pathway requires multiple ways. Another important point is the occurrence of a hydrogen bond between hydroxo/water $(\mathrm{O} 1 \mathrm{H})$ and water molecule $(\mathrm{O} 2 \mathrm{~W})$. The $\mathrm{O} 2 \mathrm{~W} \cdots \mathrm{OH}$ distance of 2.908(5) $\AA$ and the quite perfect directionality of the hydrogen bond $\left(\mathrm{O}-\mathrm{H} \cdots \mathrm{O} 2 \mathrm{~W}\right.$ angle of $\left.171(14)^{\circ}\right)$ seem to suggest that a proton transfer from $\mathrm{O} 1 \mathrm{H}$ to the "initiator" $\mathrm{O} 2 \mathrm{~W}$ happens, indicating that a hydrogen of the hydroxo/water bridged molecule in 1 plays a role, as proton injector, in the proposed mechanism.

As shown in Figure 5, the proton transfer extents to the O10W and 011 disordered water molecules located in the center of the channels, suggesting that the entire network of water molecules participates in the conduction. We suggest that the translation movement of $\mathrm{O} 10 \mathrm{w}$ and $\mathrm{O} 11$ waters along the $c$ axis around the center of the hexagonal voids (see structure refinement and Figure S7 in the Supporting Information) is consistent with proton transfer along the 1D channels and could be the key point for the proton conductivity. It is obvious to suggest that the insertion of acidic molecules, acting as proton injectors, would increase the proton conductivity value dramatically.

Theoretical Calculations. A detailed study of this type of material is not an easy task. Although some computational schemes, such as $a b$ initio and density functional theory (DFT) methods, could offer a more realistic vision of this process, they 

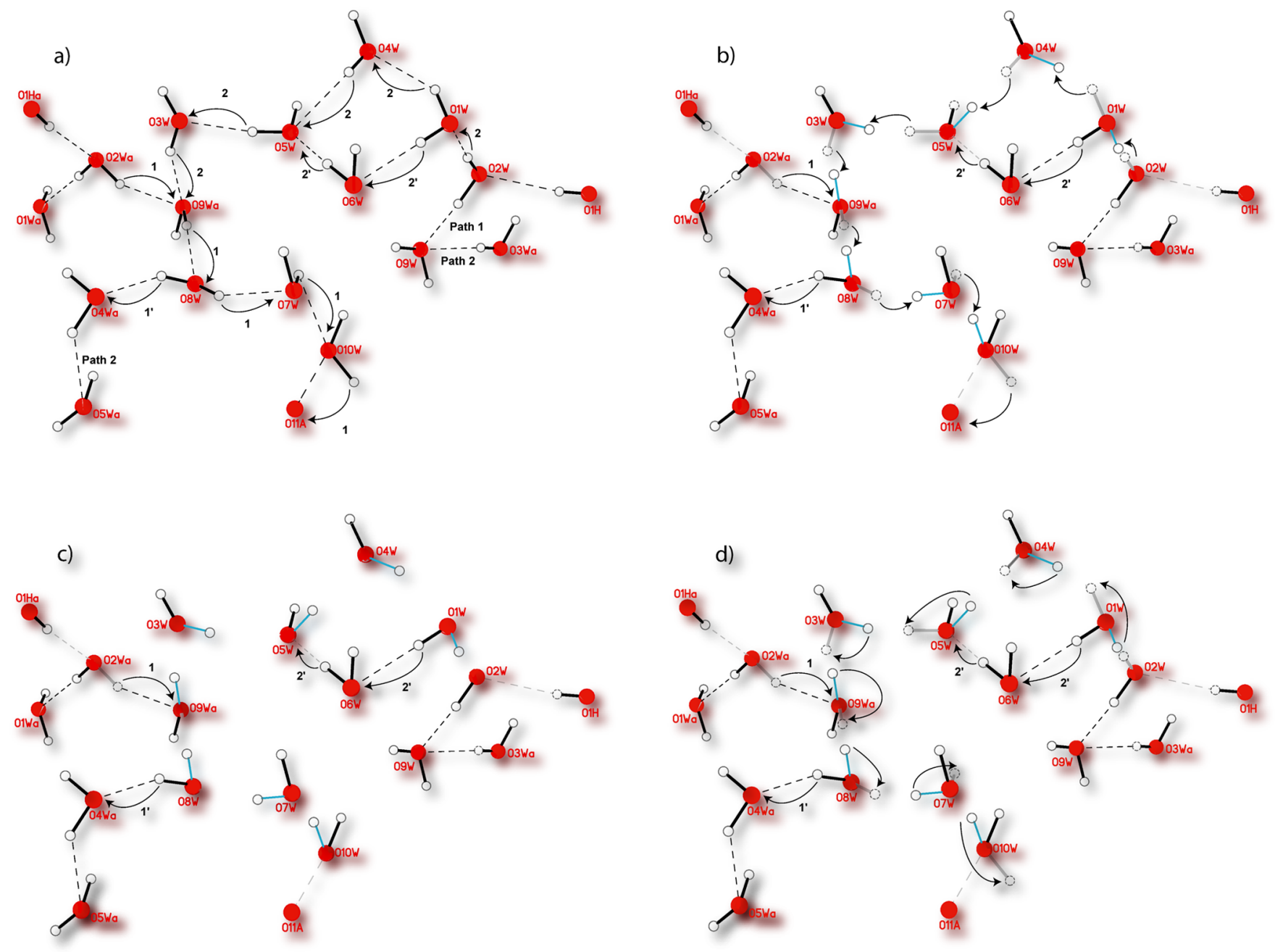

Figure 5. Complete cycle of the proton conduction showing the proton hopping between the hydrogen-bonded water/hydroxo molecules and the sequential reorientation: (a) starting real situation (data shown by crystal structure), (b, c) intermediate proposed stages where the proton hopping and the water molecules reorientation occur, and (d) recovery of the starting situation. The water molecules are represented by red filled spheres. The black, gray, and blue solid lines represent the initial (observed), the broken and the formed $\mathrm{O}-\mathrm{H}$ bonds, respectively. The dotted circles and the continuous circles represent initial and final hydrogen positions, respectively. The dotted lines represent the hydrogen bonds. [Details on $\mathrm{O} \cdots \mathrm{O}$

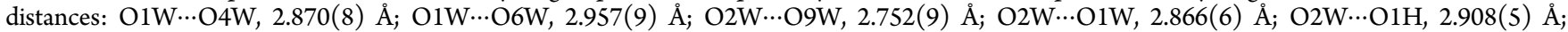

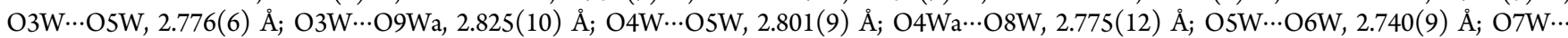

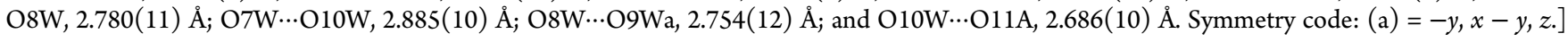

have not been considered, because of the complexity and high CPU time consumption that is implied. Thus, using quantum molecular dynamics simulations, we have found an excellent compromise alternative. This methodology has been used to contrast the proposed structure diffusion mechanism on the basis of the experimental data. This simplified model provides us with a visual and dynamic picture of the proton hopping between neighboring water molecules within the hydrogenbonded 1D arrays of water molecules hosted in the channels (see Videos S1-S6). Two different simulations were done on a fragment of the water channel, where $\mathrm{O} 2 \mathrm{~W}$ is considered as the starting point and therefore and additional hydrogen-coming from the $1 / 3$ water-bridged molecule $\mathrm{O} 1 \mathrm{H}$-was added. In the first simulation, the O11A water molecule was replaced by a hydroxo group in order to include, in a way, the attractive effect of the anode on the extra proton (see computational details, as well as Videos S1-S4). In the second one, no replacement was done to verify that the proton hopping occurs in a spontaneous manner (see Videos S5 and S6). Overall, the optimized structures shown in the videos are in agreement with the proposed structure diffusion (Grotthuss-type) mechanism ${ }^{48}$ involving the cleavage and formation of $\mathrm{O}-\mathrm{H}$ bonds, together with the hopping of the protons, followed by reorientation of the water molecules.

Even the limitations of the simplified model used, the dynamics simulation shown in Videos S1-S6 shed light on the same direction and contrast the possibility of the proposed pathways on the basis of the experimental data. In this sense, several remarkable features are clearly observed:

(i) The hopping of the protons occurs through a process of cleavage and formation of covalent $\mathrm{O}-\mathrm{H}$ bonds involving the formation of relatively small charged water clusters: $\mathrm{H}_{5} \mathrm{O}_{2}{ }^{+}$, $\mathrm{H}_{7} \mathrm{O}_{3}{ }^{+}$, and $\mathrm{H}_{9} \mathrm{O}_{4}^{+}$, followed by a solvent reorganization process; $^{52}$

(ii) The transfer of a hydrogen atom from the initiator $\mathrm{O} 2 \mathrm{~W}$ to the terminal $\mathrm{O} 10 \mathrm{~W}$, after successive proton transfers and water molecules reorientation, follows the sequence: "O2W- 
O9W-O8W-O7W-O10W", as predicted in the proposed mechanism (path 1 in Figure 5); and

(iii) The proton, upon arriving to the terminal O10W, continues on its way, along the $c$-axis to O11A, suggesting that the proton hopping continues along the disordered water molecules through the center of the channels (see Figure S7). In the two theoretical simulations, the process requires 200 and 300 fs to finish.

\section{CONCLUSIONS}

In summary, we have reported the rational design of a unique chiral 3D bioMOF. This novel material exhibits permanent porosity, high chemical, structural and water/basic media stability, and proton conductivity. Compound 1, hosting a large number of water molecules in their large pores in an ordered manner, allowed us to overcome the well-known difficulties ${ }^{28}$ to achieve detailed experimental information on the pathways involved in the hopping of protons between neighboring water molecules in a MOF during proton conduction. We propose a precise Grotthuss-like mechanism, showing the different hydrogen-bonded pathways developing inside the channels of a proton-conductive MOF. Our results highlight the importance of design-by-synthesis as a very powerful tool to understand complex physicochemical phenomena of biological and industrial interest.

\section{EXPERIMENTAL SECTION}

Preparation of $\left\{\mathrm{Cu}_{6} \mathrm{Ca}[(\mathrm{S}, \mathrm{S}) \text {-alamox }]_{3}(\mathrm{OH})_{2}\left(\mathrm{H}_{2} \mathrm{O}\right)\right\} \cdot 32 \mathrm{H}_{2} \mathrm{O}$ (1). Well-shaped hexagonal prisms of $\mathbf{1}$ suitable for $\mathrm{X}$-ray structural analysis were obtained by slow diffusion in an $\mathrm{H}$-shaped tube of aqueous solutions containing stoichiometric amounts of $\left(\mathrm{Me}_{4} \mathrm{~N}\right)_{2}\left\{\mathrm{Cu}_{2}[(S, S)\right.$ alamox $\left.](\mathrm{OH})_{2}\right\} \cdot 6 \mathrm{H}_{2} \mathrm{O}$ (see the Supporting Information) $(0.12 \mathrm{~g}, 0.18$ $\mathrm{mmol})$ in one arm and $\mathrm{CaCl}_{2}(0.01 \mathrm{~g}, 0.06 \mathrm{mmol})$ in the other. They were isolated by filtration on paper and air-dried. Yield: $2.28 \mathrm{~g}, 67 \%$; Anal.: calcd for $\mathrm{C}_{24} \mathrm{Cu}_{6} \mathrm{CaH}_{92} \mathrm{~N}_{6} \mathrm{O}_{53}$ (1734.4): C, 16.62\%; H, 5.35\%; $\mathrm{N}, 4.85 \%$. Found: C, $16.87 \%$; H, 5.21\%; N, 4.85\%; IR (KBr): $\nu=1618$ $\mathrm{cm}^{-1}(\mathrm{C}=\mathrm{O})$.

Single-Crystal X-ray Diffraction. Crystal data for 1: $\mathrm{C}_{24} \mathrm{Cu}_{6} \mathrm{CaH}_{92} \mathrm{~N}_{6} \mathrm{O}_{53}$, hexagonal, space group $P 6_{3}, a=17.6943(10)$ $\AA, c=13.2921(8) \AA, V=3604.0(5) \AA^{3}, T=90(2) \mathrm{K}, Z=2, \rho_{\text {calc }}=$ $1.598 \mathrm{~g} \mathrm{~cm}^{-3}, \mu=1.917 \mathrm{~mm}^{-1}$, Flack parameter $=0.02(1)$, of the 34464 reflections collected, 5790 are unique and 4983 observed with $I$ $>2 \sigma(I)$. Refinement of 332 parameters gave $R=0.0367$ and $R_{\mathrm{w}}=$ 0.0966 for reflections with $I>2 \sigma(I)$ and $R=0.0452$ and $R_{w}=0.1017$ for all reflections, with $S=1.062$. Further detailed information on the structural data can be found at the Supporting Information.

Proton Conductivity Studies. Electrical characterization for $\mathbf{1}$ was carried out on dense ( $\sim 96 \%-98 \%$ theoretical density) cylindrical pellets (diameter ca. $5 \mathrm{~mm}$ and thickness ca. $1 \mathrm{~mm}$ ) obtained by pressing ca. $40 \mathrm{mg}$ of sample at $250 \mathrm{MPa}$, for $1 \mathrm{~min}$. The pellets were pressed between porous $\mathrm{C}$ electrodes (Sigracet, No. GDL $10 \mathrm{BB}$, no $\mathrm{Pt})$. The sample cell was placed inside a temperature- and humiditycontrolled chamber (Espec, Model SH-222) and connected to an impedance analyzer (Agilent, Model HP4284A). AC impedance data were collected over the frequency range from $20 \mathrm{~Hz}$ to $1 \mathrm{MHz}$ with an applied voltage of $1 \mathrm{~V}$. The reproducibility of the experiments was evaluated by performing duplicate measurements in two different pellets. This may rule out extrinsic transport through the grain boundary associated with the pelletizing process, ${ }^{61}$ although singlecrystal measurements are necessary to discard interparticle conduction.

Proton conductivity measurements were carried out at different relative humidities $(\mathrm{RH}=60 \%, 70 \%, 80 \%$, and $95 \%)$ after equilibration by successive heating/cooling cycles from $21{ }^{\circ} \mathrm{C}$ to $80{ }^{\circ} \mathrm{C}$ at $0.2{ }^{\circ} \mathrm{C} /$ min. This procedure ensures stable conductivity values, being those fully reproducible after several cycles of measurements.
Impedance spectra were recorded upon cooling $\left(0.2^{\circ} \mathrm{C} / \mathrm{min}\right)$ from $80{ }^{\circ} \mathrm{C}$ to $21{ }^{\circ} \mathrm{C}$ at $5{ }^{\circ} \mathrm{C}$ intervals. The stabilization time before each data acquisition was $5 \mathrm{~min}$, with a maximum temperature variation of $0.1{ }^{\circ} \mathrm{C}$.

Computing Details. Quantum molecular dynamics simulations were performed using the SIESTA program, version 3.2, ${ }^{62}$ starting from an optimized structure. Only a hexagonal pore from the crystal structure of 1 with $64 \mathrm{H}_{2} \mathrm{O}$ molecules was chosen as a theoretical model to study the pathways involved in the proton conductivity. In order to simplify the model and to save computer processing unit (CPU) time, the walls of the channel were removed, i.e., only the water molecules were retained. In order to avoid a crumbling or large structural distribution of the system, the positions of the $\mathrm{O}$ atoms were highly constrained, whereas the $\mathrm{H}$ atoms remained free, allowing proton interchange between the neighboring molecules. The water molecule proposed as the starting proton donor into the experimental section was protonated $\left(\mathrm{H}_{3} \mathrm{O}^{+}\right)$. Two different simulations were carried out (see Videos S1-S4 and Videos S5 and S6). In order to simulate the effect of the anode when the electric voltage was applied in the measurement of the proton conductance, a water molecule in a distant place was deprotonated in one of them (a hydroxo group is considered instead of a water molecule) (Videos S1-S4). Finally, preliminary calculations with no constraints of the $\mathrm{O}$ atoms also suggested a structure diffusion mechanism. Further detailed information on the structural data can be found in the Supporting Information.

\section{ASSOCIATED CONTENT}

\section{Supporting Information}

Videos S1-S6 showing the proposed proton conduction mechanism. The Supporting Information is available free of charge on the ACS Publications website at DOI: 10.1021/ acs.chemmater.6b01286.

Additional preparations and physical characterization data of 1; additional figures (Figures S1-S7); crystallographic refinement and hydrogen bonds details for $\mathbf{1}$ (Tables S1 and S2) (PDF)

Crystallographic data (CIF)

Cambridge Crystallographic Data Centre information for CCDC-1432054 (1) (PDF)

Video S1: Proton conduction mechanism from the quantum molecular dynamics simulations showing the proton hopping between the hydrogen bonded water molecules and the sequential reorientation; oxygen and hydrogen atoms are represented by red and pink spheres, respectively (the first 200 fs of the simulation are shown) (AVI)

Video S2: Proton conduction mechanism from the quantum molecular dynamics simulations showing the proton hopping between the hydrogen bonded water molecules and the sequential reorientation; oxygen and hydrogen atoms are represented by red and pink spheres, respectively (the first 200 fs of the simulation are shown) (AVI)

Video S3: Proton conduction mechanism from the quantum molecular dynamics simulations showing the proton hopping between the hydrogen bonded water molecules and the sequential reorientation; oxygen and hydrogen atoms involved in the conducting mechanism are represented by magenta and orange spheres, respectively (the first 200 fs of the simulation are shown) (AVI)

Video S4: Proton conduction mechanism from the quantum molecular dynamics simulations showing the proton hopping between the hydrogen bonded water 
molecules and the sequential reorientation; oxygen and hydrogen atoms involved in the conducting mechanism are represented by magenta and orange spheres, respectively (the first $200 \mathrm{fs}$ of the simulation are shown) (AVI)

Video S5: Proton conduction mechanism from the quantum molecular dynamics simulations showing the proton hopping between the hydrogen bonded water molecules and the sequential reorientation; oxygen and hydrogen atoms are represented by red and pink spheres, respectively, and oxygen and hydrogen atoms involved in the conducting mechanism are represented by magenta and orange spheres, respectively (the first $300 \mathrm{fs}$ of the simulation are shown) (AVI)

Video S6: Proton conduction mechanism from the quantum molecular dynamics simulations showing the proton hopping between the hydrogen bonded water molecules and the sequential reorientation; oxygen and hydrogen atoms are represented by red and pink spheres, respectively (the first $300 \mathrm{fs}$ of the simulation are shown) (AVI)

\section{AUTHOR INFORMATION}

\section{Corresponding Authors}

*E-mail: j.gascon@tudelft.nl (J. Gascon).

*E-mail: donatella.armentano@unical.it (D. Armentano).

*E-mail: emilio.pardo@uv.es (E. Pardo).

Notes

The authors declare no competing financial interest.

\section{ACKNOWLEDGMENTS}

This work was supported by the MINECO (Spain) (Project Nos. CTQ2013-46362-P, CTQ2013-44844-P, MAT201341836-R, and Excellence Unit "Maria de Maeztu" MDM2015-0538), the Generalitat Valenciana (Spain) (Project No. PROMETEOII/2014/070), Junta de Andalucia (Spain) (Project No. FQM-1656), and the Ministero dell'Istruzione, dell'Università e della Ricerca (Italy). T.G. thanks the Universitat de València for a predoctoral contract. Thanks are also extended to the Ramón y Cajal Program and the "Convocatoria 2015 de Ayudas Fundación BBVA a Investigadores y Creadores Culturales" (E.P.). B.S. and J.G. acknowledge the financial support of the European Research Council under the European Uniońs Seventh Framework Program (No. FP/2007-2013)/ERC Grant Agreement No. 335746, CrystEng-MOF-MMM.

\section{REFERENCES}

(1) Long, J. R.; Yaghi, O. M. The Pervasive Chemistry of MetalOrganic Frameworks. Chem. Soc. Rev. 2009, 38, 1213-1214.

(2) Férey, G. Hybrid Porous Solids: Past, Present, Future. Chem. Soc. Rev. 2008, 37, 191-214.

(3) Kitagawa, S.; Matsuda, R. Chemistry of Coordination Space of Porous Coordination Polymers. Coord. Chem. Rev. 2007, 251, 24902509.

(4) Maspoch, D.; Ruiz-Molina, D.; Veciana, J. Old Materials with New Tricks: Multifunctional Open-Framework Materials. Chem. Soc. Rev. 2007, 36, 770-818.

(5) Furukawa, H.; Cordova, K. E.; O’Keeffe, M.; Yaghi, O. M. The Chemistry and Applications of Metal-Organic Frameworks. Science 2013, 341, 974.

(6) Wang, K.; Lv, X.-L.; Feng, D.; Li, J.-R.; Chen, S.; Sun, J.; Song, L.; Xie, Y.; Li, J.-R.; Zhou, H.-C. Pyrazolate-Based Porphyrinic Metal-
Organic Framework with Extraordinary Base-Resistance. J. Am. Chem. Soc. 2016, 138, 914-919.

(7) Okawa, H.; Shigematsu, A.; Sadakiyo, M.; Miyagawa, T.; Yoneda, K.; Ohba, M.; Kitagawa, H. Oxalate-Bridged Bimetallic Complexes $\{\mathrm{NH}($ prol $) 3\}[\mathrm{MCr}($ ox $) 3](\mathrm{M}=\mathrm{Mn}(\mathrm{II}), \mathrm{Fe}(\mathrm{II}), \mathrm{Co}(\mathrm{II}) ; \mathrm{NH}($ prol)3$(+)=\operatorname{tri}(3$-Hydroxypropyl)ammonium) Exhibiting Coexistent Ferromagnetism and Proton Conduction. J. Am. Chem. Soc. 2009, $131,13516-13522$.

(8) Hurd, J. a; Vaidhyanathan, R.; Thangadurai, V.; Ratcliffe, C. I.; Moudrakovski, I. L.; Shimizu, G. K. H. Anhydrous Proton Conduction at $150{ }^{\circ} \mathrm{C}$ in a Crystalline Metal-organic Framework. Nat. Chem. 2009, 1, 705-710.

(9) Kitagawa, H. Metal-Organic Frameworks: Transported into Fuel Cells. Nat. Chem. 2009, 1, 689-690.

(10) Sadakiyo, M.; Yamada, T.; Kitagawa, H. Rational Designs for Highly Proton-Conductive Metal-Organic Frameworks. J. Am. Chem. Soc. 2009, 131, 9906-9907.

(11) Ohkoshi, S.; Nakagawa, K.; Tomono, K.; Imoto, K.; Tsunobuchi, Y.; Tokoro, H. High Proton Conductivity in Prussian Blue Analogues and the Interference Effect by Magnetic Ordering. J. Am. Chem. Soc. 2010, 132, 6620-6621.

(12) Taylor, J. M.; Mah, R. K.; Moudrakovski, I. L.; Ratcliffe, C. I.; Vaidhyanathan, R.; Shimizu, G. K. H. Facile Proton Conduction via Ordered Water Molecules in a Phosphonate Metal-Organic Framework. J. Am. Chem. Soc. 2010, 132, 14055-14057.

(13) Pardo, E.; Train, C.; Gontard, G.; Boubekeur, K.; Fabelo, O.; Liu, H.; Dkhil, B.; Lloret, F.; Nakagawa, K.; Tokoro, H.; Ohkoshi, S.; Verdaguer, M. High Proton Conduction in a Chiral Ferromagnetic Metal-Organic Quartz-like Framework. J. Am. Chem. Soc. 2011, 133, $15328-15331$.

(14) Sahoo, S. C.; Kundu, T.; Banerjee, R. Helical Water Chain Mediated Proton Conductivity in Homochiral Metal-Organic Frameworks with Unprecedented Zeolitic unh-Topology. J. Am. Chem. Soc. 2011, 133, 17950-17958.

(15) Shigematsu, A.; Yamada, T.; Kitagawa, H. Wide Control of Proton Conductivity in Porous Coordination Polymers. J. Am. Chem. Soc. 2011, 133, 2034-2036.

(16) Colodrero, R. M. P.; Olivera-Pastor, P.; Losilla, E. R.; Aranda, M. a. G.; Leon-Reina, L.; Papadaki, M.; McKinlay, A. C.; Morris, R. E.; Demadis, K. D.; Cabeza, A. Multifunctional Lanthanum Tetraphosphonates: Flexible, Ultramicroporous and Proton-Conducting Hybrid Frameworks. Dalton Trans. 2012, 41, 4045-4051.

(17) Ponomareva, V. G.; Kovalenko, K. a; Chupakhin, A. P.; Dybtsev, D. N.; Shutova, E. S.; Fedin, V. P. Imparting High Proton Conductivity to a Metal-Organic Framework Material by Controlled Acid Impregnation. J. Am. Chem. Soc. 2012, 134, 15640-15643.

(18) Kim, S.; Dawson, K. W.; Gelfand, B. S.; Taylor, J. M.; Shimizu, G. K. H. Enhancing Proton Conduction in a Metal-Organic Framework by Isomorphous Ligand Replacement. J. Am. Chem. Soc. 2013, 135, 963-966.

(19) Ōkawa, H.; Sadakiyo, M.; Yamada, T.; Maesato, M.; Ohba, M.; Kitagawa, H. Proton-Conductive Magnetic Metal-Organic Frameworks, $\left\{\mathrm{NR}_{3}\left(\mathrm{CH}_{2} \mathrm{COOH}\right)\right\}\left[\mathrm{M}_{\mathrm{a}}^{\mathrm{II}} \mathrm{M}_{\mathrm{b}}^{\mathrm{III}}(\mathrm{ox})_{3}\right]$ : Effect of Carboxyl Residue upon Proton Conduction. J. Am. Chem. Soc. 2013, 135, $2256-2262$.

(20) Umeyama, D.; Horike, S.; Inukai, M.; Kitagawa, S. Integration of Intrinsic Proton Conduction and Guest-Accessible Nanospace into a Coordination Polymer. J. Am. Chem. Soc. 2013, 135, 11345-11350.

(21) Sadakiyo, M.; Yamada, T.; Kitagawa, H. Proton Conductivity Control by Ion Substitution in a Highly Proton-Conductive MetalOrganic Framework. J. Am. Chem. Soc. 2014, 136, 13166-13169.

(22) Bao, S. S.; Otsubo, K.; Taylor, J. M.; Jiang, Z.; Zheng, L. M.; Kitagawa, H. Enhancing Proton Conduction in 2D Co-La Coordination Frameworks by Solid-State Phase Transition. J. Am. Chem. Soc. 2014, 136, 9292-9295.

(23) Bazaga-García, M.; Colodrero, R. M. P.; Papadaki, M.; Garczarek, P.; Zoń, J.; Olivera-Pastor, P.; Losilla, E. R.; León-Reina, L.; Aranda, M. A. G.; Choquesillo-Lazarte, D.; Demadis, K. D.; Cabeza, A. Guest Molecule-Responsive Functional Calcium Phosphonate 
Frameworks for Tuned Proton Conductivity. J. Am. Chem. Soc. 2014, 136, 5731-5739.

(24) Tadokoro, M.; Ohhata, Y.; Shimazaki, Y.; Ishimaru, S.; Yamada, T.; Nagao, Y.; Sugaya, T.; Isoda, K.; Suzuki, Y.; Kitagawa, H.; Matsui, H. Anomalous Enhancement of Proton Conductivity for Water Molecular Clusters Stabilized in Interstitial Spaces of Porous Molecular Crystals. Chem.-Eur. J. 2014, 20, 13698-13709.

(25) Maxim, C.; Ferlay, S.; Tokoro, H.; Ohkoshi, S.-I.; Train, C. Atypical Stoichiometry for a 3D Bimetallic Oxalate-Based Long-Range Ordered Magnet Exhibiting High Proton Conductivity. Chem. Commun. 2014, 50, 5629-5632.

(26) Nagarkar, S. S.; Unni, S. M.; Sharma, A.; Kurungot, S.; Ghosh, S. K. Two-in-One: Inherent Anhydrous and Water-Assisted High Proton Conduction in a 3D Metal-Organic Framework. Angew. Chem., Int. Ed. 2014, 53, 2638-2642.

(27) Phang, W. J.; Lee, W. R.; Yoo, K.; Ryu, D. W.; Kim, B.; Hong, C. S. pH-Dependent Proton Conducting Behavior in a Metal-Organic Framework Material. Angew. Chem., Int. Ed. 2014, 53, 8383-8387.

(28) Sadakiyo, M.; Yamada, T.; Honda, K.; Matsui, H.; Kitagawa, H. Control of Crystalline Proton-Conducting Pathways by WaterInduced Transformations of Hydrogen-Bonding Networks in a Metal-Organic Framework. J. Am. Chem. Soc. 2014, 136, 7701-7707.

(29) Tang, Q.; Liu, Y.; Liu, S.; He, D.; Miao, J.; Wang, X.; Yang, G.; Shi, Z.; Zheng, Z. High Proton Conduction at above $100^{\circ} \mathrm{C}$ Mediated by Hydrogen Bonding in a Lanthanide Metal-Organic Framework. J. Am. Chem. Soc. 2014, 136, 12444-12449.

(30) Sadakiyo, M.; Kasai, H.; Kato, K.; Takata, M.; Yamauchi, M. Design and Synthesis of Hydroxide Ion-Conductive Metal-Organic Frameworks Based on Salt Inclusion. J. Am. Chem. Soc. 2014, 136, $1702-1705$.

(31) Borges, D. D.; Devautour-Vinot, S.; Jobic, H.; Ollivier, J.; Nouar, F.; Semino, R.; Devic, T.; Serre, C.; Paesani, F.; Maurin, G. Proton Transport in a Highly Conductive Porous Zirconium-Based MetalOrganic Framework: Molecular Insight. Angew. Chem. 2016, 128, 3987-3992.

(32) McKinlay, A. C.; Morris, R. E.; Horcajada, P.; Férey, G.; Gref, R.; Couvreur, P.; Serre, C. BioMOFs: Metal-Organic Frameworks for Biological and Medical Applications. Angew. Chem., Int. Ed. 2010, 49, 6260-6266.

(33) Imaz, I.; Rubio-Martínez, M.; An, J.; Solé-Font, I.; Rosi, N. L.; Maspoch, D. Metal-Biomolecule Frameworks (MBioFs). Chem. Commun. 2011, 47, 7287-7302.

(34) Persch, E.; Dumele, O.; Diederich, F. Molecular Recognition in Chemical and Biological Systems. Angew. Chem., Int. Ed. 2015, 54, 3290-3327.

(35) Makarević, J.; Jokić, M.; Perić, B.; Tomišić, V.; Kojić-Prodić, B.; Žinić, M. Bis(Amino Acid) Oxalyl Amides as Ambidextrous Gelators of Water and Organic Solvents: Supramolecular Gels with Temperature Dependent Assembly/Dissolution Equilibrium. Chem. - Eur. J. 2001, 7, 3328-3341.

(36) Grancha, T.; Ferrando-Soria, J.; Cano, J.; Lloret, F.; Julve, M.; De Munno, G.; Armentano, D.; Pardo, E. Enantioselective SelfAssembly of Antiferromagnetic hexacopper(II) Wheels with Chiral Amino Acid Oxamates. Chem. Commun. 2013, 49, 5942-5944.

(37) Grancha, T.; Ferrando-Soria, J.; Castellano, M.; Julve, M.; Pasán, J.; Armentano, D.; Pardo, E. Oxamato-Based Coordination Polymers: Recent Advances in Multifunctional Magnetic Materials. Chem. Commun. 2014, 50, 7569-7585.

(38) Rouquerol, J.; Avnir, D.; Fairbridge, C. W.; Everett, D. H.; Haynes, J. H.; Pernicone, N.; Ramsay, J. D. F.; Sing, K. S. W.; Unger, K. K. Recommendations for the Characterization of Porous Solids. Pure Appl. Chem. 1994, 66, 1739-1758.

(39) De Lange, M. F.; Vlugt, T. J. H.; Gascon, J.; Kapteijn, F. Adsorptive Characterization of Porous Solids: Error Analysis Guides the Way. Microporous Mesoporous Mater. 2014, 200, 199-215.

(40) Cheng, L. S.; Yang, R. T. Improved Horvath-Kawazoe Equations Including Spherical Pore Models for Calculating Micropore Size Distribution. Chem. Eng. Sci. 1994, 49, 2599-2609.
(41) Horike, S.; Umeyama, D.; Kitagawa, S. Ion Conductivity and Transport by Porous Coordination Polymers and Metal-Organic Frameworks. Acc. Chem. Res. 2013, 46, 2376-2384.

(42) Colomban, P.; Novak, A. Proton Transfer and Superionic Conductivity in Solids and Gels. J. Mol. Struct. 1988, 177, 277-308.

(43) Munakata, H.; Chiba, H.; Kanamura, K. Enhancement on Proton Conductivity of Inorganic-organic Composite Electrolyte Membrane by Addition of Sulfonic Acid Group. Solid State Ionics 2005, 176, 2445-2450.

(44) Gosalawit, R.; Chirachanchai, S.; Shishatskiy, S.; Nunes, S. Krytox-Montmorillonite-Nafion Nanocomposite Membrane for Effective Methanol Crossover Reduction in DMFCs. Solid State Ionics 2007, 178, 1627-1635.

(45) Dai, C.-A.; Liu, C.-P.; Lee, Y.-H.; Chang, C.-J.; Chao, C.-Y.; Cheng, Y.-Y. Fabrication of Novel Proton Exchange Membranes for DMFC via UV Curing. J. Power Sources 2008, 177, 262-272.

(46) Hara, N.; Ohashi, H.; Ito, T.; Yamaguchi, T. Rapid Proton Conduction through Unfreezable and Bound Water in a Wholly Aromatic Pore-Filling Electrolyte Membrane. J. Phys. Chem. B 2009, $113,4656-4663$.

(47) Kreuer, K.; Rabenau, A.; Weppner, W. Vehicle Mechanism, A New Model for the Interpretation of the Conductivity of Fast Proton Conductors. Angew. Chem., Int. Ed. Engl. 1982, 21, 208-209.

(48) Agmon, N. The Grotthuss Mechanism. Chem. Phys. Lett. 1995, 244, 456-462.

(49) Marx, D. Proton Transfer 200 Years after von Grotthuss: Insights from $A b$ Initio Simulations. ChemPhysChem 2006, 7, 18481870.

(50) Tuckerman, M. E. On the Quantum Nature of the Shared Proton in Hydrogen Bonds. Science 1997, 275, 817-820.

(51) Marx, D.; Tuckerman, M. E.; Hutter, J.; Parrinello, M. The Nature of the Hydrated Excess Proton Inwater. Nature 1999, 397, 601-604.

(52) Hassanali, A.; Giberti, F.; Cuny, J.; Kühne, T. D.; Parrinello, M. Proton Transfer through the Water Gossamer. Proc. Natl. Acad. Sci. U. S. A. 2013, 110, 13723-13728.

(53) Vilčiauskas, L.; Tuckerman, M. E.; Bester, G.; Paddison, S. J.; Kreuer, K.-D. The Mechanism of Proton Conduction in Phosphoric Acid. Nat. Chem. 2012, 4, 461-466.

(54) Fujiyoshi, Y.; Murata, K.; Mitsuoka, K.; Hirai, T.; Walz, T.; Agre, P.; Heymann, J. B.; Engel, A. Structural Determinants of Water Permeation through Aquaporin-1. Nature 2000, 407, 599-605.

(55) Gordon, R. E.; Strange, J. H. Fast Hydrogen Ion Diffusion in Solid Hydrogen Uranyl Phosphate (HUP). Solid State Commun. 1979, 31, 995-997.

(56) Kreuer, K. D.; Rabenau, A.; Messer, R. Proton Conductivity in the Layer Compound $\mathrm{H}_{3} \mathrm{OUO}_{2} \mathrm{AsO}_{4} \cdot 3 \mathrm{H}_{2} \mathrm{O}$ (HU As). Appl. Phys. A: Solids Surf. 1983, 32, 45-53.

(57) Capelli, S. C.; Falvello, L. R.; Forcén-Vázquez, E.; McIntyre, G. J.; Palacio, F.; Sanz, S.; Tomás, M. Proton Cascade in a Molecular Solid: H/D Exchange on Mobile and Immobile Water. Angew. Chem., Int. Ed. 2013, 52, 13463-13467.

(58) Ogawa, T.; Kamiguchi, K.; Tamaki, T.; Imai, H.; Yamaguchi, T. Differentiating Grotthuss Proton Conduction Mechanisms by Nuclear Magnetic Resonance Spectroscopic Analysis of Frozen Samples. Anal. Chem. 2014, 86, 9362-9366.

(59) Ogawa, T.; Aonuma, T.; Tamaki, T.; Ohashi, H.; Ushiyama, H.; Yamashita, K.; Yamaguchi, T. The Proton Conduction Mechanism in a Material Consisting of Packed Acids. Chem. Sci. 2014, 5, 4878-4887.

(60) Liang, X.; Zhang, F.; Feng, W.; Zou, X.; Zhao, C.; Na, H.; Liu, C.; Sun, F.; Zhu, G. From Metal-organic Framework (MOF) to MOF-polymer Composite Membrane: Enhancement of LowHumidity Proton Conductivity. Chem. Sci. 2013, 4, 983-992.

(61) Tominaka, S.; Cheetham, A. K. Intrinsic and Extrinsic Proton Conductivity in Metal-Organic Frameworks. RSC Adv. 2014, 4, 54382-54387.

(62) Artacho, E.; Cela, J. M.; Gale, J. D.; García, A.; Junquera, J.; Martin, R. M.; Ordejón, P.; Sánchez-Portal, D.; Soler, J. M. SIESTA 3.2, 2012 . 